\title{
Percentage problems in bridging courses
}

\section{Farida Kachapova $^{a^{*}}$ and Ilias Kachapov ${ }^{b}$}

\author{
${ }^{a}$ School of Computing and Mathematical Sciences, Auckland University of \\ Technology, Auckland, New Zealand; ${ }^{b}$ Examination Academic Services, University \\ of Auckland, Auckland, New Zealand
}

* Corresponding author. Email: farida.kachapova@aut.ac.nz

\section{Pre-print version}

Published in International Journal of Mathematical Education in Science and Technology, ISSN 1464-5211 (electronic), 0020-739X (paper), Volume 43, Issue 5, 654-663, URL: http://www.tandfonline.com/doi/abs/10.1080/0020739X.2011.618554

\section{(Received 2011)}

\begin{abstract}
Research on teaching high school mathematics shows that the topic of percentages often causes learning difficulties. This paper describes a method of teaching percentages that the authors used in university bridging courses. In this method the information from a word problem about percentages is presented in a two-way table. Such a table gives a logical structure to the problem and provides an algorithm for finding a simple equation for the unknown value of interest. The use of this procedure is illustrated by several examples of different levels of difficulty. The method can be applied to many types of percentage problems, so it is quite universal.
\end{abstract}

Keywords: percentage; proportion; table; bridging course; problem-solving; percentage increase; percentage decrease; profit; bank interest

\section{Introduction}

Research on teaching high school mathematics has identified some topics causing particular learning difficulties. Ratio and proportion were included in the list of such 
topics in the well known study by Hart [1]. Students also have difficulties with the related concept of percentage, as shown in studies [2]-[6]. These studies investigate different strategies in teaching percentages. In [6] they suggested a method that “... put more emphasis on why percentages are used than on how they are calculated." They also concluded: "Calculation skills are another area requiring attention..." [6].

In this paper we suggest an approach that helps students to improve calculation skills in percentage problems with different contexts. In this approach the quantitative information from a problem is presented in a two-way table, then the table is used to derive an equation and calculate the value in question. This method is algorithmic and quite universal, it works for most standard problems about percentages. The authors successfully use this approach in university bridging courses that help students to fill gaps in their knowledge of high school mathematics.

\section{Description of the method}

We suggest using two-way tables to solve typical problems about percentages. Such a table has two parallel columns: one contains amounts with units such as $\mathrm{kg}, \mathrm{cm}, \$$, and the other contains corresponding percentages. All the information given in the problem is entered in the table together with $x$ denoting the unknown value of interest. Next, we highlight an important square, that is the square with four nonblank cells, which contains $x$. The following steps complete the solution.

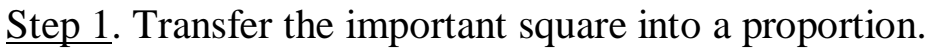

Step 2. Cross-multiply and get an equation.

Step 3. Solve the equation for $x$.

The following example demonstrates this procedure.

Example 1. A jar contains $4 \mathrm{~kg}$ of salt solution with concentration of $3 \%$. How much salt is in the jar? 
Solution: We create a two-way table, which shows the amounts of salt and solution in kilograms and percentages:

\begin{tabular}{|c|c|c|}
\hline & $\mathrm{kg}$ & $\%$ \\
\hline Salt & $x$ & 3 \\
\hline Solution & 4 & 100 \\
\hline
\end{tabular}

Table 1.

The information from the question was entered in the table with $x$ for the amount of salt. In this simple case the important square contains all four numerical cells of the table:

\begin{tabular}{|c|c|}
\hline$x$ & 3 \\
\hline 4 & 100 \\
\hline
\end{tabular}

Table 2.

Step 1. Transfer the important square into a proportion: $\frac{x}{4}=\frac{3}{100}$.

Step 2. Cross-multiply and get an equation: $100 x=4 \times 3$.

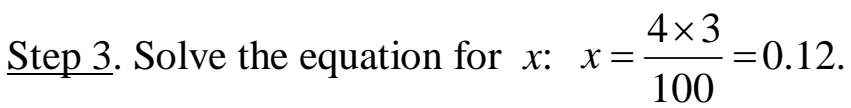

There is $0.12 \mathrm{~kg}$ of salt in the jar.

Later we will apply the method to more sophisticated problems. The advantage of the method is its versatility. High school courses (see for example [7] - [9]) usually teach percentages as several sub-topics such as:

1) calculating percentages 'of' quantities,

2) working out the 'original' quantity,

3) increasing and decreasing by percentages,

4) calculating percentage changes,

5) calculating percentage profit, 
6) calculating bank interest, etc.

The described technique of two-way tables applies to all these types of problems and does not require identifying a sub-topic or memorizing the corresponding instructions. The students only have to create a two-way table, fill it with given information, possibly perform a couple of simple additions or subtractions and follow the described Steps 1-3. This procedure is more straightforward and less mistakeprone than usual instructions in textbooks such as: "To calculate a percentage of a given quantity, multiply the quantity by the percentage. The percentage can be written as a fraction or decimal first." [8].

\section{Application to standard problems}

Next we illustrate the method with further examples in the increasing order of difficulty.

Example 2. Helen banked $\$ 84$ but spent $35 \%$ of this money. How much is left in the bank?

Solution: We create a two-way table:

\begin{tabular}{|c|c|c|}
\hline & $\$$ & $\%$ \\
\hline Banked & 84 & 100 \\
\hline Spent & & 35 \\
\hline Left & $x$ & $100-35=65$ \\
\hline
\end{tabular}

Table 3.

This is the important square (it is also highlighted in the table above):

\begin{tabular}{|c|c|}
\hline 84 & 100 \\
\hline$x$ & 65 \\
\hline
\end{tabular}

Table 4.

Step 1. Transfer the important square into a proportion: $\frac{84}{x}=\frac{100}{65}$. 
Step 2. Cross-multiply and get an equation: $100 x=84 \times 65$.

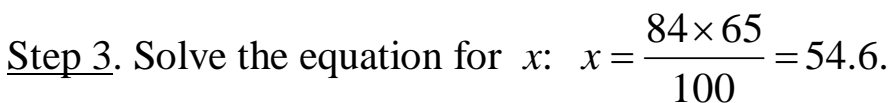

There is $\$ 54.60$ left in the bank.

Example 3. Ben paid for a ticket $\$ 15$ plus $40 \%$ of its price. What is the price of the ticket?

Solution: We create a two-way table:

\begin{tabular}{|c|c|c|}
\hline & $\$$ & $\%$ \\
\hline Total price & $x$ & 100 \\
\hline Part paid in dollars & 15 & $100-40=60$ \\
\hline Part paid in percents & & 40 \\
\hline
\end{tabular}

Table 5.

The important square is highlighted in the table above.

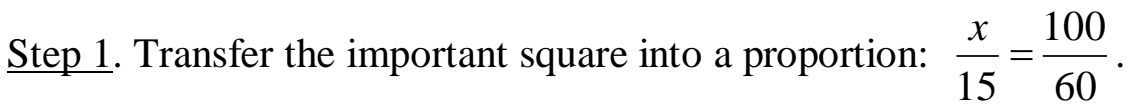

Step 2. Cross-multiply and get an equation: $60 x=15 \times 100$.

Step 3. Solve the equation for $x: x=\frac{15 \times 100}{60}=25$.

The price of the ticket is $\$ 25$.

Example 4. John borrowed $\$ 1200$ and after one full year he paid back $\$ 1560$. What rate of interest was used?

Solution: This is a two-way table:

\begin{tabular}{|c|c|c|}
\hline & $\$$ & $\%$ \\
\hline Borrowed & 1200 & 100 \\
\hline Paid back & 1560 & \\
\hline Interest & $1560-1200=360$ & $x$ \\
\hline
\end{tabular}

Table 6. 


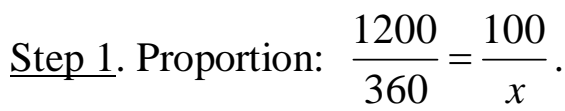

Step 2. Cross-multiply: $1200 x=360 \times 100$.

Step 3. Solve the equation: $x=\frac{360 \times 100}{1200}=30$.

The interest rate is $30 \%$.

Example 5. If a house is sold for $\$ 352,000$ there is a loss of $20 \%$ on the cost price. For how much should it be sold to make a gain of $20 \%$ on the cost price?

Solution: This is a two-way table:

\begin{tabular}{|c|c|c|}
\hline & $\$$ & $\%$ \\
\hline Cost price & & 100 \\
\hline Losing price & 352,000 & $100-20=80$ \\
\hline Gaining price & $x$ & $100+20=120$ \\
\hline
\end{tabular}

Table 7.

Step 1. Proportion: $\frac{352,000}{x}=\frac{80}{120}$.

Step 2. Cross-multiply: $80 x=352,000 \times 120$.

Step 3. Solve the equation: $x=\frac{352,000 \times 120}{80}=528,000$.

The price should be $\$ 528,000$.

\section{Application to more difficult problems}

The described method also works well on harder problems such as percentage puzzles in [10]. Sometimes a problem about percentages requires a longer table or more than one table.

Example 6. Fresh fruit contains $72 \%$ of water and dried fruit contains $20 \%$ of water. How much dried fruit can you get from $20 \mathrm{~kg}$ of fresh fruit? 
Solution: Denote $x(\mathrm{~kg})$ the amount of pure fruit in $20 \mathrm{~kg}$ of fresh fruit. It remains the same in the dried fruit. We create two tables.

\begin{tabular}{|c|c|c|}
\hline & $\mathrm{kg}$ & $\%$ \\
\hline Pure fruit & $x$ & $100-72=28$ \\
\hline Water & & 72 \\
\hline Total & 20 & 100 \\
\hline
\end{tabular}

Table 8. Fresh fruit

Proportion: $\frac{x}{20}=\frac{28}{100} ;$ cross-multiply: $100 x=20 \times 28 ; x=\frac{20 \times 28}{100}=5.6$.

\begin{tabular}{|c|c|c|}
\hline & $\mathrm{kg}$ & $\%$ \\
\hline Pure fruit & $x=5.6$ & $100-20=80$ \\
\hline Water & & 20 \\
\hline Total & $y$ & 100 \\
\hline
\end{tabular}

Table 9. Dried fruit

Proportion: $\frac{5.6}{y}=\frac{80}{100} ;$ cross-multiply: $80 y=5.6 \times 100 ; \quad y=\frac{5.6 \times 100}{80}=7$.

You can get $7 \mathrm{~kg}$ of dried fruit.

Example 7. The price of a product was increased by $60 \%$. By what percent should the new price be decreased to get the initial price?

Solution: Denote $a$ the initial price in dollars. We create two tables.

\begin{tabular}{|c|c|c|}
\hline & $\$$ & $\%$ \\
\hline Initial price & $a$ & 100 \\
\hline Increase & & 60 \\
\hline New price & $x$ & $100+60=160$ \\
\hline
\end{tabular}

Table 10. Price increase

Proportion: $\frac{a}{x}=\frac{100}{160} ;$ cross-multiply: $100 x=160 a ; x=\frac{160 a}{100}=1.6 a$. 


\begin{tabular}{|c|c|c|}
\hline & $\$$ & $\%$ \\
\hline New price & $1.6 a$ & 100 \\
\hline Decrease & $1.6 a-a=0.6 a$ & $y$ \\
\hline Decreased price $=$ initial price & $a$ & \\
\hline
\end{tabular}

Table 11. Price decrease

Proportion: $\frac{1.6 a}{0.6 a}=\frac{100}{y} ;$ cross-multiply: $1.6 y=0.6 \times 100 ; \quad y=\frac{0.6 \times 100}{1.6}=37.5$.

The new price should be decreased by $37.5 \%$.

Alternative solution: This problem can be solved with one big table combining the previous two tables:

\begin{tabular}{|c|c|c|c|c|}
\hline & $\$$ & $\%$ & $\$$ & $\%$ \\
\hline Initial price & $a$ & 100 & & \\
\hline Increase & & 60 & & \\
\hline New price & $x$ & $100+60=160$ & $x$ & 100 \\
\hline Decrease & & & $x-a$ & $y$ \\
\hline Decreased price $=$ initial price & & & $a$ & \\
\hline
\end{tabular}

Table 12.

The dollar amount $x$ for the increased price is the same throughout the table while its percent value is not. We can create two proportions from this table, then find an expression for $x$ and the value of $y$.

$$
\begin{aligned}
& \frac{a}{x}=\frac{100}{160}, \quad x=\frac{160 a}{100}=1.6 a . \\
& \frac{x}{x-a}=\frac{100}{y}, \quad \frac{1.6 a}{1.6 a-a}=\frac{100}{y}, \quad \frac{1.6 a}{0.6 a}=\frac{100}{y}, \quad y=\frac{0.6 \times 100}{1.6}=37.5 .
\end{aligned}
$$

The new price should be decreased by $37.5 \%$. 
Example 8. In April an airline increased all of its fares by $20 \%$. In September of the same year, the airline reduced all of its fares by $10 \%$. What was the net percentage increase in September from the initial price?

Solution: Denote $a$ the initial price in dollars. This is a two-way table:

\begin{tabular}{|c|c|c|c|c|c|c|}
\hline & $\$$ & $\%$ & $\$$ & $\%$ & $\$$ & $\%$ \\
\hline Initial price & $a$ & 100 & & & $a$ & 100 \\
\hline Increase & & 20 & & & \\
\cline { 1 - 5 } Increased price & $x$ & $100+20=120$ & $x$ & 100 & & \\
\cline { 1 - 4 } Decrease & & $y$ & $100-10=90$ & $y$ & $z$ \\
\hline Decreased price & & & & & \\
\hline
\end{tabular}

Table 13.

We create three proportions from this table, then find expressions for $x, y$ and the value of $z$.

$$
\begin{aligned}
& \frac{a}{x}=\frac{100}{120}, \quad x=\frac{120 a}{100}=1.2 a . \\
& \frac{x}{y}=\frac{100}{90}, \quad y=\frac{90 x}{100}=\frac{90 \times 1.2 a}{100}=1.08 a . \\
& \frac{a}{y}=\frac{100}{z}, \quad z=\frac{100 y}{a}=\frac{100 \times 1.08 a}{a}=108 . \quad 108-100=8 .
\end{aligned}
$$

The increase was $8 \%$.

Example 9. The marked price on an item was decided so as to gain $25 \%$ profit on the cost price. During a sale the marked price was reduced by $10 \%$ to $\$ 45$. What is the item's cost?

Solution: This is a two-way table: 


\begin{tabular}{|c|c|c|c|c|}
\hline & $\$$ & $\%$ & $\$$ & $\%$ \\
\hline Cost & $x$ & 100 & & \\
\cline { 1 - 2 } Intended profit & & 25 & & \\
\hline Marked price & $y$ & $100+25=125$ & $y$ & 100 \\
\hline Reduction & & & 10 \\
\hline Selling price & & 45 & $100-10=90$ \\
\hline
\end{tabular}

Table 14.

We create two proportions from this table, then find the values of $y$ and $x$ :

$$
\begin{aligned}
& \frac{y}{45}=\frac{100}{90}, \quad y=\frac{45 \times 100}{90}=50 . \\
& \frac{x}{y}=\frac{100}{125}, \quad \frac{x}{50}=\frac{100}{125}, \quad x=\frac{50 \times 100}{125}=40 .
\end{aligned}
$$

The cost is $\$ 40$.

Example 10. A shopkeeper got $5 \%$ profit after selling an item with $25 \%$ reduction. What percentage profit was intended on this item before the reduction?

Solution: This is a two-way table:

\begin{tabular}{|c|c|c|c|c|}
\hline & $\$$ & $\%$ & $\$$ & $\%$ \\
\hline Cost & $a$ & 100 & & \multirow{2}{*}{} \\
\hline Profit & & 5 & & \\
\hline Selling price & $x$ & $100+5=105$ & $x$ & $100-25=75$ \\
\hline Reduction & & & & 25 \\
\hline Marked price & $y$ & & $y$ & 100 \\
\hline Intended profit & $y-a$ & $z$ & & \\
\hline
\end{tabular}

Table 15.

We create three proportions from this table, then find expressions for $x, y$ and the value of $z$.

From the $1^{\text {st }}$ and $2^{\text {nd }}$ highlighted yellow rows: $\frac{a}{x}=\frac{100}{105}, \quad x=\frac{105 a}{100}=1.05 a$. 
From the blue important square: $\frac{x}{y}=\frac{75}{100}, \quad y=\frac{100 x}{75}=\frac{100 \times 1.05 a}{75}=1.4 a$.

From the $1^{\text {st }}$ and $3^{\text {rd }}$ highlighted yellow rows:

$$
\frac{a}{y-a}=\frac{100}{z}, \quad z=\frac{100 \times(y-a)}{a}=\frac{100 \times(1.4 a-a)}{a}=40 .
$$

The intended profit was $40 \%$.

Example 11. There are two alloys of zinc, copper and pewter of weights $300 \mathrm{~kg}$ and $200 \mathrm{~kg}$, respectively. The first piece contains 50\% of copper and the second piece contains $25 \%$ of zinc. The percentage of pewter in the second piece is twice the percentage of pewter in the first piece. When the two pieces are alloyed together, the new alloy will contain $28 \%$ of pewter. Find the amount of copper in the new alloy.

Solution: Denote $a$ the percentage of pewter in the first piece. Then this percentage in the second piece equals $2 a$. We find both percentages using the following table:

\begin{tabular}{|c|c|c|c|c|c|c|}
\hline & \multicolumn{2}{|c|}{ Piece 1} & \multicolumn{2}{|c|}{ Piece 2} & \multicolumn{2}{|c|}{$\begin{array}{c}\text { Total: } \\
\text { New alloy }=\text { Piece } 1+\text { Piece } 2\end{array}$} \\
\hline & $\mathrm{kg}$ & $\%$ & $\mathrm{~kg}$ & $\%$ & $\mathrm{~kg}$ & $\%$ \\
\hline Zinc & & & & 25 & & \\
\hline Copper & & 50 & & & & \\
\hline Pewter & $x$ & $a$ & $y$ & $2 a$ & $x+y$ & 28 \\
\hline Total & 300 & 100 & 200 & 100 & $300+200=500$ & 100 \\
\hline
\end{tabular}

Table 16.

Using the highlighted important squares we create three proportions and find expressions for $x, y$ and the value of $a$ :

$$
\begin{aligned}
& \frac{x}{300}=\frac{a}{100}, \quad x=\frac{300 a}{100}=3 a . \\
& \frac{y}{200}=\frac{2 a}{100}, \quad y=\frac{200 \times 2 a}{100}=4 a . \text { So } x+y=7 a .
\end{aligned}
$$




$$
\frac{x+y}{500}=\frac{28}{100}, \quad \frac{7 a}{500}=\frac{28}{100}, \quad a=\frac{500 \times 28}{7 \times 100}=20 .
$$

We are interested in the amounts of copper in Piece 1 and Piece 2, so we denote them $X$ and $Y$ respectively. Next we re-write the table (only the columns for Piece 1 and Piece 2) replacing $a$ by 20:

\begin{tabular}{|c|c|c|c|c|}
\hline & \multicolumn{2}{|c|}{ Piece 1 } & \multicolumn{2}{c|}{ Piece 2 } \\
\hline & $\mathrm{kg}$ & $\%$ & $\mathrm{~kg}$ & $\%$ \\
\hline Zinc & & & & 25 \\
\hline Copper & $X$ & 50 & $Y$ & $100-25-40=35$ \\
\hline Pewter & & 20 & & 40 \\
\hline Total & 300 & 100 & 200 & 100 \\
\hline
\end{tabular}

Table 17.

We create two proportions and calculate the values of $X$ and $Y$ :

$$
\begin{array}{ll}
\frac{X}{300}=\frac{50}{100}, & X=\frac{300 \times 50}{100}=150 . \\
\frac{Y}{200}=\frac{35}{100}, & Y=\frac{200 \times 35}{100}=70 .
\end{array}
$$

So the amount of copper in the new alloy equals $X+Y=150+70=220(\mathrm{~kg})$.

\section{Discussion}

When we use a table, we present information from a word problem in a more transparent and logical form. Using such a table, it is easy to complete the solution following a few simple steps. Filling a table and following the algorithmic steps is easier than solving each type of percentage problems as a unique question (e.g. deciding when to divide and when to multiply) or using lengthy instructions from textbooks. The main challenge for the students applying this method is filling the table properly; it usually gets easier when the students learn to assign $100 \%$ correctly, e.g. to a total amount or an old price. In our practice the students understand the idea 
of the method after 2-3 examples and apply it confidently. The authors use the described approach in university bridging courses. Formal statistical analysis of the effectiveness of this approach was not done yet but our case studies show that applying this method helps the students to improve their problem-solving skills, which in turn helps them to improve their general understanding of percentages. Mastering the described tables with percentages makes it easier for the students to study tables with conditional probabilities in probability courses, since there are similarities between the two types of tables.

\section{References}

[1] K.M. Hart (Ed.), Children's Understanding of Mathematics: 11-16, Murray, London, 1982.

[2] M. Parker and G. Leinhardt, Percent: A privileged proportion, Review of Educational Research 65 (1995), pp. 421-482.

[3] J. Moss and R. Case, Developing children's understanding of the rational numbers: A new model and an experimental curriculum, J. For Research in Mathematics Education 30 (1999), pp. 122-147.

[4] J. Moss and B. Caswell, Connecting linear measurement to the learning of ratio and proportion by building percent dolls, Teaching Children Mathematics 10 (2) (2004), pp. 68-74.

[5] S. Dole, Promoting Percent as a Proportion in Eighth-Grade Mathematics, School Science and Mathematics 10 (7) (2000), pp. 345-396.

[6] P. White and M. Mitchelmore, Teaching percentage as a multiplicative relationship, Conference Proceedings of Mathematics Education Research Group of Australasia (MERGA) (2005), pp. 783-790. 
[7] D. Barton, Alpha Mathematics, $2^{\text {nd }}$ ed., Pearson Education, New Zealand, 2009.

[8] D. Barton, Beta Mathematics, $2^{\text {nd }}$ ed., Pearson Education, New Zealand, 2008.

[9] D. Barton, Gamma Mathematics, $2^{\text {nd }}$ ed., Pearson Education, New Zealand, 2010.

[10] S. Klymchuk, Money Puzzles, Maths Press, New Zealand, 2001. 